\title{
Unha cirúrgica de biopolímero de cana de açúcar para preservação do leito ungueal após avulsão
}

\section{Surgical nail of biopolymer from sugarcane for preservation of the nail bed after avulsion}

\author{
Flavia Cristina Morone Pinto' • Márcia Oliveira²
}

\section{RESUMO}

Objetivo: Desenvolver uma unha cirúrgica de BPCA com o propósito de produzir uma cobertura para o leito ungueal imediatamente exposto após avulsão da lâmina ungueal. Método: A unha cirúrgica de BPCA foi produzida a partir do gel de BPCA, que tem propriedades viscoelásticas e é estável em concentrações de $0,6 \%$ e $0,8 \%$. Resultados: $A$ comprovada biocompatibilidade e a baixa toxicidade do polissacarídeo celulósico permitem idealizar a sua utilização como um dispositivo médico, servindo como barreira mecânica, proteção do leito ungueal e remodelação da lâmina ungueal. As características físico-químicas do polissacarídeo permitem a produção de um modelo ungueal autoaderente e resistente, servindo temporariamente como substituto da lâmina ungueal.Além disso, o custo da unha cirúrgica de BPCA é acessível. Conclusão:A unha cirúrgica de BPCA parece ser uma alternativa promissora para manutenção e cicatrização do leito ungueal.

Palavras-chave: Doenças da Unha; Biopolímeros; Saccharum; Curativos Oclusivos; Cicatrização.

\begin{abstract}
Objective: Develop a surgical nail of BPCA with the purpose of producing a cover for the nail bed immediately exposed after avulsion of the nail plate. Method:The surgical nail of BPCA was produced from the BPCA gel, which has viscoelastic properties and is stable at concentrations of $0.6 \%$ and $0.8 \%$. Results: The biocompatibility and low toxicity of the cellulosic polysaccharide allow to idealize its use as a medical device, serving as a mechanical barrier, protection of the nail bed and remodeling of the nail plate. The physico-chemical characteristics of the polysaccharide allow the production of a self-adhesive and resistant nail model, serving temporarily as a substitute for the nail plate. In addition, the cost of the surgical nail of BPCA is affordable. Conclusion:The surgical nail of BPCA appears to be a promising alternative for maintenance and healing of the nail bed.
\end{abstract}

Keywords: Nail Diseases; Biopolymers; Saccharum; Occlusive Dressings; Wound Healing. 


\section{INTRODUÇÃO}

A unha é um anexo cutâneo dotado de sensorialidade e que exerce proteção da falange distal contra impactos traumáticos, auxilia na função de pinça de pequenos objetos, colabora com a sensibilidade fina e contribui para a aparência de mãos e pés ${ }^{(1-2)}$.

Do ponto de vista epidemiológico, a maioria das lesões de unha é causada por trauma e envolve, particularmente crianças e adultos jovens ${ }^{(3)}$.A avulsão após trauma do aparelho ungueal pode ser necessária para a avaliação da estabilidade do leito ungueal ou para drenar um possível hematoma ${ }^{(4)}$.

Dentre os procedimentos cirúrgicos do aparelho ungueal, a avulsão da lâmina ungueal é o mais realizado( ${ }^{(5)}$. Suas indicações têm finalidades diagnósticas e terapêuticas ${ }^{(6)}$.

A própria lâmina ungueal removida pode ser utilizada como aparato de proteção, desde que em boas condições para recobrir o leito exposto ${ }^{(7)}$. $\mathrm{Na}$ impossibilidade disto, alguns materiais têm sido sugeridos, porém, muitas vezes, indisponíveis no momento da cirurgia e com alto custo associado.

Estudos anteriores mostram que um exopolissacarídeo celulósico obtido a partir do melaço da cana de açúcar, pela síntese de bactérias Gram negativas do gênero Zoogloea pertencentes à família Pseudomonadaceae, proporcionou uma adequada cicatrização às feridas cutâneas em animais, otimizando o tempo de cicatrização e promovendo o controle de infecção( ${ }^{(8)}$. Outros estudos ${ }^{(9-1)}$ mostram que o biopolímero de cana de açúcar (BPCA) foi eficiente como barreira mecânica e adjunto no tratamento de lesões ulceradas.

A questão norteadora do estudo é desenvolver uma unha cirurgica de BPCA capaz de manter o leito ungueal, auxiliar na cicatrização, evitar aderências, de modo a diminuir a dor pós-operatória e melhorar a sensação táctil. Objetivou-se desenvolver uma unha cirúrgica de BPCA com o propósito de produzir uma cobertura para o leito ungueal imediatamente exposto após avulsão da lâmina ungueal.

\section{MÉTODO}

\section{A unha cirúrgica de BPCA}

Trata-se de um polissacarídeo obtido a partir do melaço de cana de açúcar sintetizado por bactéria, sendo denominado de biopolímero de cana de açúcar (BPCA).

$A$ unha cirúrgica de BPCA foi produzida a partir do gel de BPCA que tem propriedades viscoelásticas e é estável em concentrações de $0,6 \%$ e $0,8 \%$ nas temperaturas usuais de armazenamento e em fluidos biológi$\cos \left(0-40^{\circ} \mathrm{C}\right)$. Essas propriedades o tornam aplicável in vivo(12). Devido à sua composição química e propriedades físicas, o BPCA não induz respostas imunes e, portanto, tem sido considerado um biomaterial promissor com uma ampla gama de aplicações em ciências biológicas e médicas ${ }^{(13)}$.

Os testes biomecânicos com análise de parâmetros como a velocidade de tração, a força de ruptura máxima e a força máxima de deformação específica, mostraram que a membrana de BPCA tem resultados semelhantes ao politetrafluoroetileno expandido - ePTFE(14).

A citotoxicidade do BPCA foi testada in vitro pela produção de óxido nítrico, taxa de adesão e viabilidade celular de macrófagos alveolares com baixa toxicidade no ensaio MTT - 3-(4,5-dimetiltiazol-2yl)-2,5-difenil brometo de tetrazolina ${ }^{(15)}$. Em outro estudo ${ }^{(16)}$, os autores também concluíram que o BPCA foi seguro quando administrado por via oral em ratos a $2000 \mathrm{mg} / \mathrm{kg}$ de peso corporal em uma única dose, não foi citotóxico pelo teste de atividade de lactato desidrogenase (LDH) e mostrou um efeito protetor contra mielotoxicidade e genotoxicidade induzida pela ciclofosfamida.

As unhas cirúrgicas foram produzidas em forma de placas de $3 \times 3 \mathrm{~cm}$ de tamanho e espessura de $1 \mathrm{~mm}$. Flexíveis e moldáveis de acordo com o tamanho e formato do leito ungueal descoberto, apresentando uma superfície superior multiperfurada e uma inferior esponjosa, facilitando a drenagem de exsudatos e auto aderência ao leito (Figura I).

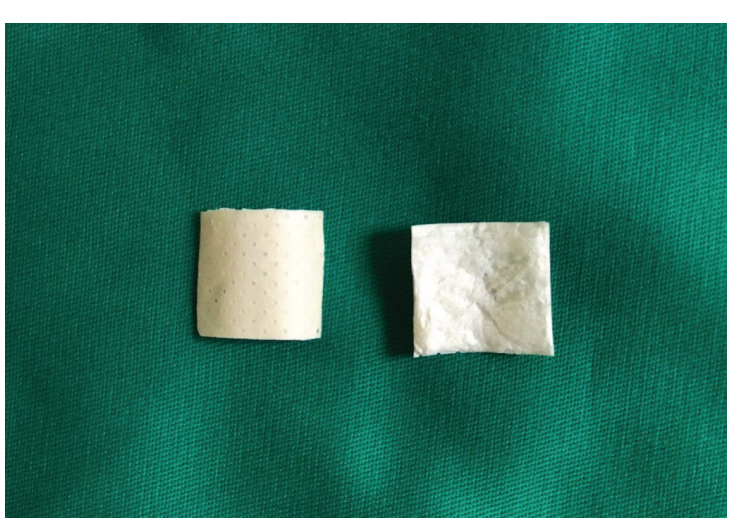

FIGURA 1 - Curativo Ungueal de Biopolímero de Cana de Açúcar.: a) Superfície superior, multiperfurada: facilita a drenagem de exsuldato; b) Superfície inferior, esponjosa: promove aderência ao leito ungueal. 
As unhas cirúrgicas de BPCA foram embaladas individualmente em envelopes do tipo grau cirúrgico e esterilizados previamente com irradiação gama de $25 k G y^{(1)}$.

Foram fabricadas e doadas pela POLISA ${ }^{\odot}$ Biopolímeros para Saúde, startup incubada na Estação Experimental de Cana de Açúcar de Carpina, vinculada a Universidade Federal Rural de Pernambuco (EECAC/UFRPE).

\section{Procedimentos e Variáveis}

Após avulsão da unha, de acordo com as variadas técnicas, a área será lavada com solução salina e suavemente seca com gaze. Então, as unhas cirúrgicas de BPCA serão aplicadas sobre o leito ungueal envolvendo toda a superfície desnuda, sem a necessidade de fixação por sutura. Depois será realizada a cobertura com gaze e bandagem de crepe superposta (curativo secundário). Os pacientes serão instruídos a permanecer por $\mathbf{4 8}$ horas sem trocar o curativo, podendo este permanecer mais tempo, desde que em condições clínicas favoráveis.

O perfil sociodemográfico dos participantes incluídos na pesquisa será traçado, além de serem submetidos a aferições clínicas (peso e altura) e laboratoriais (Hematócrito - Htc, Hemoglobina - Hgb, Glicemia de jejum GJ, razão normalizada internacional - INR), sendo os parâmetros clínicos avaliados como base no MEASURE ${ }^{(17)}$. Também será acompanhado o tempo de permanência da unha cirúrgica de BPCA ao leito ungueal.

O projeto de pesquisa clínica foi submetido e aprovado pelo Comitê de Ética para Pesquisa com Seres Humanos (CEP/CCS/UFPE: CEP I.50I.560). Os dados apresentados neste artigo referem-se à ao desenvolvimento da prótese, ou seja, da unha cirúrgica de BPCA.

\section{Resultados Esperados e Discussão}

Após trauma, a produção de uma nova unha é suspensa por, aproximadamente, 21 dias. Em seguida, é observado um aumento na taxa de crescimento nos próximos 50 dias e um decréscimo nos 30 dias subsequentes. $O$ crescimento das unhas torna-se normal 100 dias após a ocorrência do trauma ${ }^{(18)}$.

Quando ocorre a avulsão cirúrgica ou traumática da placa ungueal, a lâmina poderá ser reposta sobre o leito ungueal desde que esteja em boas condições, porém, se esta possibilidade não existir, a unha deverá ser substituída para que a integridade do aparelho ungueal seja mantida durante o processo de cicatrização, proporcionando o crescimento de uma unha saudável. Com este propósito, alguns materiais vêm sendo utilizados: esponja de poliuretano, gaze não aderente, próteses acrílicas, pedaços de filme de radiografia e polipropileno flexível ${ }^{(7,19)}$. As próteses ungueais INRO ${ }^{\circledR}$ foram desenvolvidas para atender esta demanda, porém seu custo é alto e, muitas vezes, indisponíveis durante a cirurgia ${ }^{(20)}$. Por outro lado, a unha cirúrgica de BPCA tem baixo custo, pois derivam de processo fermentativo a partir do melaço da cana de açúcar, produto local e de fonte renovável. $O$ custo da prótese $I N_{R O}{ }^{\circledR}$ é de USD 52,80 (aproximadamente $R \$ 218,00$ ) a unidade, enquanto que o custo estimado para a unha de BPCA é de $R \$ 50,00$.

Espera-se com a utilização da unha cirúrgica de BPCA: manter o formato original do leito ungueal, auxiliar na recuperação de um leito ungueal saudável, evitar aderências entre a cutícula e o leito ungueal proximal, apoiar uma possível fratura da falange distal, diminuir a dor pós-operatória, e melhorar a sensação táctil durante o período de cicatrização( ${ }^{(7)}$. $O$ mau funcionamento do aparelho ungueal ocasiona sintomatologia dolorosa, requerendo atenção médica especializada, sendo a avulsão o procedimento cirúrgico mais frequente, com reflexos na capacidade laborativa individual e com impacto socioeconômico.

O BPCA em estado de pureza apresenta elasticidade, resistência à tração, flexibilidade e ainda pode ser modelado em diferentes formas, características físico-químicas fundamentais para a confecção de implantes biológi$\cos ^{(9,11)}$. Destaca-se ainda, a composição deste polímero que apresenta apenas polissacarídeos, diferentemente de outros polímeros biológicos ${ }^{(21)}$.

Disponibilizado em forma de gel, esponja, membrana e películas, o BPCA vem sendo utilizado em projetos de pesquisa como curativos cirúrgicos, com base em dados comprovados em diferentes aplicações experimentais e clínicas ${ }^{(9-11)}$.

A comprovada biocompatibilidade e a baixa toxicidade do polissacarídeo celulósico permitem idealizar a sua utilização como um dispositivo médico, servindo como barreira mecânica, proteção do leito ungueal e remodelação da lâmina ungueal. As características físico-químicas do polissacarídeo permitem a produção de um modelo ungueal autoaderente e resistente, servindo temporariamente como substituto da lâmina ungueal. Além disso, o custo da unha cirúrgica de BPCA é acessível.

\section{AGRADECIMENTOS}

Pesquisa realizada em colaboração com o Laboratório de Imunopatologia Keizo Asami (LIKA) da Universidade Federal de Pernambuco, Recife / PE, Brasil, Departamento de Energia Nuclear (DEN) e Centro de Tecnologia e Geociências (CTG) da Universidade Federal de Pernambuco (UFPE), Recife / PE, Brasil.

\section{CONFLITOS DE INTERESSE}

Os autores declaram não haver conflitos de interesse. 


\section{REFERÊNCIAS}

I Nail Surgery Clin Dermatol. 20 I3; 3I (5):5 I5-25.

2 Rich P, Jefferson JA. Overview of nails disorders. UP to Date [Internet]; Atualizado em Dez, 2013. [acesso em $13 \mathrm{dez}$ 2013]. Disponível em: http://www.uptodate.com/contents/ overview-of-nail-disorders?source $=$ search_result\&sear$\mathrm{ch}=$ unha\&selectedTitle $=|\% 7 E| 50$.

3 Salazard B, Launay F, Desouches C, Samson P, Jouve JL, Magalon G. Fingertip injuries in children: 8 I cases with at least one -year follow-up. Rev Chir Orthop Reparatrice Appar Mot. 2004; 90(7):621-7.

4 Tucker DJ, Jules KT, Raymond F. Nailbed injuries with hallucal phalangeal fractures-evaluation and treatment. J Amer Podiatric Assoc. 1996; 86: 170-3.

5 Pandhi D, Verma P. Nail avulsion: indications and methods. Indian J Dermatol,Venereol Leprol. 2012; 78(3):299-308.

6 Haneke E. Surgical anatomy of the nail apparatus. Dermatol Clin. 2006; 24:29I-6.

7 Tos P, Titolo P, Chirila NL, Catalano F, Artiaco S. Surgical treatment of acute fingernail injuries.J Orthop Traumatol. 2012; 13(2):57-62.

8 Monteiro VLC, Coelho M, Carrazzoni PG, Mota RA, Melo FAD, Carvalho EC,Andrade EC, Andrade LSS. Cana-de-açúcar no tratamento de feridas cutâneas por segunda ou terceira intenção. Med veterinária. 2007; I (I): I-8.

9 Teixeira FMF, Pereira MF, Ferreira NLG, Miranda GM,Aguiar JLA. Spongy film of cellulosic polysaccharide as a dressing for aphthous stomatitis treatment in rabbits. Acta Cir Bras. 2014; 29:23I-6.

10 Cavalcanti LM, Pinto FCM, Oliveira GM, Lima SVC, Aguiar JLA, Lins. Efficacy of bacterial cellulose membrane for the treatment of lower limbs chronic varicose ulcers: a randomized and controlled trial. Rev. Col. Bras. Cir. [Internet]. 2017 Feb [cited 2018 Feb 19]; 44(I): 72-80. Available from: -./http://www.scielo.br/scielo.php?script=sci_arttext\&pi$d=S 0100-699|2017000| 00072 \& \operatorname{lng}=$ en.http://dx.doi. org/10.1590/0100-6991201700101।

II Martins AGS, Lima SVC, Araujo LAP, Vilar FO, Cavalcante NTPA. Wet dressing for hypospadias surgery. Int Braz J Urol. 2013; 39:408-13.

12 Cordeiro-Barbosa FA, Aguiar JLA, Lira MMM, Pontes Filho NT, Bernardino-Araújo S. Use of a gel biopolymer for the treatment of eviscerated eyes: experimental model in rabbits. Arq. Bras. Oftalmol [Internet]. 2012 [cited 2014 Aug 14]; 75(4): 267-272. Available from: http://www.scielo.br/pdf/ abo/v75n4/10.pdf

I3 Lee KY, Buldum G, Mantalaris A, Bismarck A. More than meets the eye in bacterial cellulose: biosynthesis, bioprocessing, and applications in advanced fiber composites. Macromol Biosci [Internet]. 2014 Jan; I4(I):10-32. doi: http://dx.doi. org/l0.1002/mabi.201300298

14 Falcão SC, Coelho ARB, Evêncio Neto J. Biomechanical evaluation of microbial cellulose (Zoogloea sp.) and expanded polytetrafluoroethylene membranes as implants in repair of produced abdominal wall defects in rats. Acta Cir Bras [Internet]. 2008; 23(2): 184-191. doi: http://dx.doi.org//0.1590/S010286502008000200012

15 Castro CMMB, Aguiar JLA, Melo FAD, Silva WTF, Marques E, Silva DB. Sugar cane biopolymer cytotoxicity. I An. Fac. Med. Univ. Fed. Pernamb. 2004; 49(2): I 19-1 23.

16 Pinto FCM, Oliveira ACAX, Carvalho RR, Gomes-Carneiro MR, Lima SVC, Paumgartten FJR, Aguiar JLA. Acute toxicity, cytotoxicity, genotoxicity and antigenotoxic effects of a cellulosic exopolysaccharide obtained from sugarcane molasses. Carbohydrate Polymers [Internet]. 2016 Feb.; 137:55660. doi: http://dx.doi.org//0.1016/j.carbpol.2015.10.07।

17 Keast DH, Bowering CK, et al. MEASURE: $A$ proposed assessment framework for developing best practice recommendations for wound assessment. Wound Repair regen. 2004; 12(3) I17.

18 Baden HP. Regeneration of the nail. Arch Dermatol. 1965; 91:619-20.

19 Tos P, Artiaco S, Coppolino S, Conforti LG, Battiston B. A simple sterile polypropylene fingernail substitute. Chir Main. 2009; 28(3): : 143-5.

20 Ogunro EO. External fixation of injured nail bed with the INRO surgical nail splint.J Hand Surg. 1989; |4:236-41.

2I Lucena MT, Melo Júnior MR, Lira MMM, Castro CMMB, Cavalcanti LA, Menezes MA, et al. Biocompatibility and cutaneous reactivity of cellulosic polysaccharide film in induced skin wounds in rats. J Mater Sci Mater Med [Internet]. 2015; 26(2):82. Available from: http://link.springer.com/10.1007/ sl0856-015-5410-x. 